\title{
IMAGING IN A CASE OF RATHKE'S CLEFT CYST
}

\author{
Mohammed Darwish ${ }^{1}$, Rajesh Venunath², Sri Krishna U. ${ }^{3}$, Rohini A. ${ }^{4}$
}

1 Postgraduate Student, Department of Radio-diagnosis, K. S. Hedge Medical Academy, Mangaluru, Karnataka, India.

${ }^{2}$ Assistant Professor, Department of Radio-diagnosis, K. S. Hedge Medical Academy, Mangaluru, Karnataka, India.

${ }^{3}$ Professor, Department of Radio-diagnosis, K. S. Hedge Medical Academy, Mangaluru, Karnataka, India.

${ }^{4}$ Assistant Professor, Department of Radio-diagnosis, K. S. Hedge Medical Academy, Mangaluru, Karnataka, India.

HOW TO CITE THIS ARTICLE: Darwish M, Venunath R, Krishna SU, et al. Imaging in a case of rathke's cleft CYST. J. Evolution Med. Dent. Sci. 2019;8(30):2436-2437, DOI: 10.14260/jemds/2019/533

\section{BACKGROUND}

Epithelium-lined cysts that arise from the embryologic remnants of the Rathke's pouch within the pituitary gland form the Rathke's cleft cysts. They are non-neoplastic and are also known as pars intermedia cysts, which can be located in the sellar or suprasellar region. Rathke cleft cysts are frequently seen and are found in $\sim 15 \%$ (range $11-22 \%$ ) of autopsies done.(1,2) The major chunk of Rathke's cleft cysts diagnosed is identified incidentally on imaging of the brain or pituitary gland done for other reasons.

Although the basic element is congenital, they are rarely identified in childhood as they are more likely to grow in size as age progresses.(3) The likelihood of the diagnosis is twice as much in females as compared to male with a ratio of 2:1. The most common presenting symptoms for patients with Rathke's cleft cysts are headache; and visual disturbances like bitemporal hemianopia which are due to compression of the optic chiasma.

One of the congenital disorders of the pituitary gland during the development of the adenohypophysis is the Rathke's cleft cyst. Rathke's cleft cysts can have variable MRI signal, which often hinder the differential diagnosis and are often confused with other cystic lesions of the pituitary gland.

In this article, we discuss the MRI findings of a pathologically proven case of Rathke's cleft cyst in a 45-yearold male patient with complaints of headache and visual disturbances. These cysts are often confusing and differentiating them from other intrasellar or suprasellar masses is often cumbersome on radiological studies.

\section{PRESENTATION OF CASE}

A 45-year-old male presented to the ENT Department of our institution with history of recurrent headache and visual disturbances in both eyes. His vitals were stable and neurological examination revealed no obvious cranial nerve palsies or sensory or motor deficits. Local examination of the globes was unremarkable. Visual evaluation shows a field defect in bilateral temporal regions. He was initially sent of CT and later MRI evaluation as a part of the evaluation protocol.

'Financial or Other Competing Interest': None.

Submission 14-03-2019, Peer Review 09-07-2019,

Acceptance 15-07-2019, Published 29-07-2019.

Corresponding Author:

Dr. Mohammed Darwish,

1402, Inland Ebony, Near Mangala Hospital,

Kadri Road, Mangalore,

Karnataka, India.

E-mail: drmohammeddarwish@gmail.com

DOI: $10.14260 /$ jemds/2019/533

\section{CT}

Axial non contrast enhanced CT section were obtained in GE Brightspeed 16 slice Multidetector CT scanner. The imaging reveals a large well-defined hypodense cyst of 20-25HU causing expansion of the sella with suprasellar extension causing erosion of the anterior and posterior clinoid process. Superiorly, the lesion is seen to reach up to the level of the floor of third ventricle. No obvious extension into the sphenoid sinus seen inferiorly.

No areas of calcification seen.

\section{MRI}

MRI brain with gadolinium was performed in a Siemens Magnetom Avanto 1.5 Tesla scanner. The study reveals a a large well defined rounded cystic lesion, measuring $2.9 \times 3.3$ $X 3.5 \mathrm{~cm}$ (APXTSXCC) (Volume=16 $\mathrm{ml}$ ), arising from the pituitary gland causing expansion of the sella turcica of sphenoid bone with extension into the suprasellar cistern, appearing hyperintense on T1, T2 and FLAIR sequences with a peripheral thin hypointense capsule showing no diffusion restriction. No internal septations or calcifications were seen within it. Laterally the lesion was seen separate from the cavernous sinus with no significant encasement of the supraclinoid internal carotid arteries.

The lesion was seen indenting laterally on bilateral hippocampus at the region of sylvian fissure. Superiorly, the lesion is seen reaching up to the floor of third ventricle with mass effect on optic chiasma. Inferiorly, the lesion was seen abutting the roof of sphenoid sinus. No areas of blooming were noted in SWI sequences and the normal pituitary stalk or pituitary gland was not visualised.

The patient underwent excision of the lesion and was histologically proved to be an epithelial cyst possible a Rathke's cleft cyst.

\section{DISCUSSION}

Rathke's cleft cysts develop as a congenital rostral outpouching of the primitive oral cavity during the third or fourth week of gestation, which occurs due to failure of obliteration of the lumen of Rathke's pouch. They are nonneoplastic and may be seen as sellar and suprasellar cystic lesions.

The remnant of the Rathke's pouch which is a precursor to the anterior lobe, intermediate lobe, and pars tuberalis of the pituitary gland forms the epithelium of the Rathke's cleft cyst. The anterior lobe and the pars tuberalis of the pituitary gland forms from the proliferation of the anterior wall and the pars intermedia forms from the proliferation of the posterior wall of the Rathke's pouch; which maintains a central embryonic cleft between the anterior and posterior walls. 
The lumen that remains after the formation of the lobes reduces to a tapered cleft like structure called Rathke's cleft and it mostly regresses. In a scenario where this cleft persists and becomes bigger a Rathke's cleft cyst is diagnosed, which may become symptomatic depending on the size.

Studies describing another developmental origin for the Rathke's cleft cyst can be seen in literature where authors have described it developing directly from the neuroepithelial tissue due to metaplasia of the anterior pituitary cells or the endoderm. $(4,5)$

Histologically the wall of the Rathke's cleft cysts is similar to the wall of embryonic cleft having a single cell layer. This single cell layer of epithelium is most often ciliated and often contains goblet cells.

Histopathologically the typical presentation of the Rathke's cleft cysts is columnar epithelium which is tall and well-differentiated with cilia and also goblet cells are seen. Frequent alteration of this classical pathological presentation occurs due to squamous metaplasia.(6)

Most Rathke's cleft cysts are asymptomatic and measure $3 \mathrm{~mm}$ in diameter. In pituitary glands examined randomly at autopsy Rathke's cleft cysts are present in $13 \%$ to $22 \%$ of the autopsies conducted which were of asymptomatic people. $(7,8)$ Symptomatic Rathke's cleft cysts are rare. If symptomatic, it is generally caused by large cysts causing compression on the hypothalamus, the stalk or the pituitary gland itself. And these symptomatic patients usually present with headache, visual disturbance, hypopituitarism and/or diabetes insipidus. (9.10)

MR findings of Rathke's cleft cyst are a non-enhancing cystic lesion displaying variable fluid signal intensities on T1 and T2 weighted images, located in the in sellar or suprasellar region. The lesion may show hyperintense signal intensity on T2 weighted images in $70 \%$ of the cases with iso to hypointense signal intensity on $\mathrm{T} 2$ weighted images in $30 \%$ of the cases and hyperintense signal intensity on T1 weighted images in $50 \%$ of the cases.

Approximately $75 \%$ of the cases show a small nonenhancing intra-cystic solid nodule which appears hyperintense on T1WI \& hypointense on T2WI which is practically pathognomonic of a Rathke's cleft cyst. However, such a nodule was not evident in the case we studied. A thin rim of peripheral enhancement surrounding the cyst maybe seen and that represents the compressed pituitary gland around the lesion.

If the fluid within the cyst were subjected to biochemical analysis it would reveal high mucopolysaccharide and cholesterol content giving it a short relaxation time and thus leading to high signal intensity on T1 weighted images. (11,12)

Other cystic lesions of the pituitary gland like cystic pituitary adenomas and cystic craniopharyngiomas are usually difficult to differentiate from Rathke's cleft cysts on imaging studies; and cystic craniopharyngiomas also commonly exhibit a solid nodule within, confounding matters even more. Even though craniopharyngiomas are typically a lobulated, well-defined, cystic lesion with a solid mural nodule; the nodules of craniopharyngiomas display hypointense signal intensity on T1-weighted images and hyperintense signal intensity on T2-weighted images. They also display intense heterogeneous enhancement post intravenous contrast administration. $(13,14)$

And hence the characteristic signal intensities on magnetic resonance imaging of an intra-cystic solid nodule in a Rathke's cleft cyst if present, maybe highly suggestive of the diagnosis.

\section{CONCLUSIONS}

As far as surgery is concerned, a Rathke's cleft cyst is approached differently as compared to other sellar and parasellar lesions like craniopharyngiomas or pituitary adenomas. Prior to surgery, having the correct diagnosis or differential diagnosis is necessary for neurosurgeons when deciding on the approach for surgery and appropriateness of treatment. The fluid within a Rathke's cleft cyst displays inconsistent signal intensities on MR imaging and therefore arriving at the right diagnosis solely relying on the signal intensities on these images becomes a rather complex issue. A solid nodule within the Rathke's cleft cyst is a frequent finding and identifying these nodules as having their distinctive MR signal intensities, such as hyperintensity on T1WI and hypointensity on T2WI, could be a very dependable sign in order to clinch the diagnosis.

\section{REFERENCES}

[1] Shanklin WM. On the presence of cysts in the human pituitary. Anat Rec 1949;104(4):399-407.

[2] Baskin DS, Wilson CB. Transsphenoidal treatment of non-neoplastic intrasellar cysts. J Neurosurg 1984;60(1):8-13.

[3] Hardy J, Vezina JL. Transsphenoidal neurosurgery of intracranial neoplasm. Adv Neurol 1976;15:261-73.

[4] Shuangshoti S, Netsky MG, Nashold BS Jr. Epitherial cysts related to sella turcica. Proposed origin from neuroepithelium. Arch Pathol 1970;90(5):444-50.

[5] Rasmussen AT. Ciliated epithelium and mucus secreting cells in the human hypophysis. Anat Rec 1929;41:273-83.

[6] Burger PC, Scheithauer BW. Benign cystic lesions. In: Rosai J, edr. Tumors of the Central Nervous System. $1^{\text {st }}$ edn. Washington: AFIP 1993: p. 355-70.

[7] Hald JK, Eldevik OP, Skalpe IO. Craniopharyngioma identification by CT and MR imaging at $1.5 \mathrm{~T}$. Acta Radiologica 1995;36(2):142-7.

[8] Osborn AG. Miscellaneous tumors, cysts and metastases. In: Patterson AS, edr. Diagnostic Neuroradiology. $1^{\text {st }}$ edn. St. Louis: Mosby 1994: p. 62670.

[9] Sumida M, Uozumi T, Mukada K, et al. Rathke cleft cysts: correlation of enhanced MR and surgical findings. AJNR Am J Neuroradiol 1994;15(3):525-32.

[10] Kuwahara T, Shinohara Y, Sugiura M, et al. A Rathke's cleft cyst with a moving mass in the cyst. No Shinkei Geka 1997;25(2):177-80.

[11] Nemoto Y, Inoue Y, Fukuda T, et al. MR appearance of Rathke's cleft cysts. Neuroradiology 1988;30(2):1559.

[12] Hayashi Y, Tachibana O, Muramatsu N, et al. Rathke cleft cyst: MR and biomedical analysis of cyst content. J Comput Assist Tomogr 1999;23(1):34-8.

[13] Kucharczyk W, Peck WW, Kelly WM, et al. Rathke cleft cysts: CT, MR imaging and pathologic features. Radiology 1987;165(2):491-5.

[14] Hua F, Asato R, Miki Y, et al. Differentiation of suprasellar nonneoplastic cysts from cystic neoplasms by Gd-DTPA MRI. J Comput Assist Tomogr 1992;16(5):744-9. 